Rakenteiden Mekaniikka (Journal of Structural Mechanics)

Vol. 50, No 3, 2017, pp. $234-238$

https://rakenteidenmekaniikka.journal.fi/index

https://doi.org/10.23998/rm. 64621

(c) The author(s) 2017.

Open access under CC BY-SA 4.0 license.

\title{
Wärtsilä digital design platform
}

\author{
Juho Könnö ${ }^{1}$, Hannu Tienhaara and Tero Frondelius
}

Summary. We discuss a methodology for systematically using an Simulation Process and Data Management (SPDM) platform in product development. The purpose of this paper is to get the reader acquianted with the concept and the importance of such an approach. The target is to base product development on clearly defined targets and requirements in different phases of the product development lifecycle. This is achieved by means of a data-centered approach where all data is retained in a digital form in the platform. Instead of reporting, users are provided with different views to the same data. We will discuss how a static document-based validation system can be replaced by a common validation data platform. In addition, we aim to base the validation requirements on a reliability analysis workflow.

In this case, the platform is used not only to handle the simulation data but to encompass the whole product validation scope. To this end, the fundamental concept of our data management approach is to couple the requirements directly to the simulations and handle all the design decision data together with the simulations using these to drive the design.

The motivation for the activity is a dramatic reduction in product development time based on a possibly longer concept phase but less iterations during the detail design phase. Future developments will include moving also the physical testing data and coupling that with the corresponding simulations and validation requirements.

Key words: SPDM, product development lifecycle, PLM, simulation workflows, data management

Received 15 June 2017. Accepted 11 August 2017. Published online 21 August $201 \%$.

\section{Introduction}

Currently, speed is of the essence in product development. The number of custom solutions and different product configurations is growing all the time, hence the importance of rapid development cycles is a business-critical aspect in product design. Simultaneously, the number of customer-specific requirements imposed on a single product are growing both in number and complexity. For example, in the power generation setting, let it be for marine or stationary power, the importance of loading patters as a design constraint is of great importance in analyzing the structural integrity of components $[6,3]$. Similar approaches to simulation data management are discussed e.g. in [2] and [9]

To succeed in simulation-driven development, it is essential that the turnaround time for a single simulation is low enough. On the technical level, this can be achieved by

${ }^{1}$ Corresponding author. juho.konno@wartsila.com 
simplifying the models used in the early design phase - often a non-trivial task in its own right [5]. Our aim is to minimize this non-productive time spent by using an SPDM system to simplify the validation workflow and simultaneously assure the quality and reliability of the results. The basic dataflow in planning and running the validation workflow for a specific product development project is outlined in Figure 1 illustrating the whole validation and design loop from requirements to design and the related data flow presented by the arrows. The green activities take place in the Product Data Management (PDM) system, whilst the blue activities are governed in the SPDM system, with orange arrows presenting the data flow both the task management and to the PDM system for recording design data.

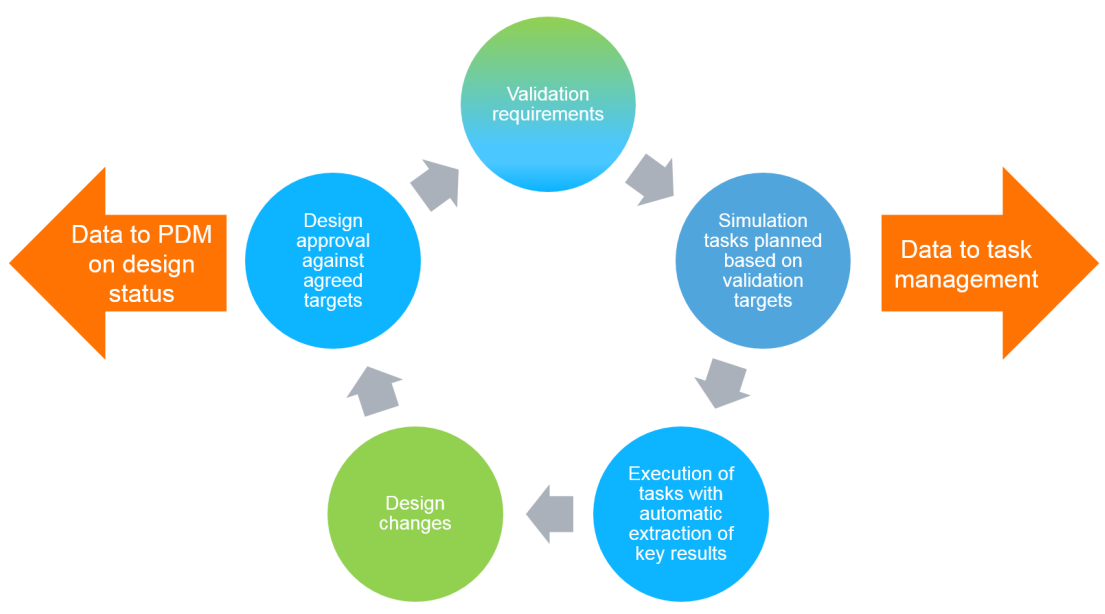

Figure 1. Basic data flow in the requirements-based validation SPDM system

The existence of a single platform as the enterprise-wide solution is quite rare. In reality, the software landscape consists of several tools from different vendors, linked with varying levels of automation, usually by point-to-point integrations. Typically, this leads to severe inefficiencies in the data-flow between different departments and design teams. Quite often critical data is lost somewhere along the way which directly translates to costly delays in new product introduction. As pointed out by [4], one of the key elements for a successful Product Lifecycle Management (PLM), and thus also an SPDM system, is the cohesion between different product views, let it be mechanical design, automation, electrical or bill of materials, to name a few. In the validation setting, this translates to the key concept of knowing what needs to be validated and, most importantly, how. Only then one should go to planning, not happily skipping the aforementioned two critical steps.

\section{Simulation process and data management solution}

To handle the complexity created by the abundance of software platforms, we have chosen a data-centered approach as the backbone of our SPDM framework. The key concept is that whatever data, which can be huge [1], the users are accessing, it is stored in a unique location, but the users are provided with different views to that specific information regardless of the system they are are working in. This also means that we strive to end altogether document-based simulation reporting since, once you transfer the data into a 
document, you are also disconnecting it from the original source of truth, the simulation itself. We will now focus on three key points of making the system successful.

The first key aspect, albeit not traditionally seen so much belonging to the SPDM domain, is having all requirements visible and synchronized in the validation data management system. Although it makes sense to divide requirements into different levels to handle them efficiently, the link between the high-level business requirement and the low-level validation requirements should never be broken. As an example of this, we can take the thermal load on combustion engine components [8] which effectively dictates the lifetime of a given component. That lifetime prediction [10] is not a number in its own right but a result of a chain of simulations, going from fatigue and finite element analysis to a computational fluid mechanics combustion simulation which, in its turn, takes its input from a one-dimensional performance simulation. When looking at the inputs of that performance simulation, we are actually looking already at the high-level product requirements, such as fuel consumption targets. Similarly, our solution to, e.g., increasing the lifetime by a different choice of material [7] has a direct link to the product cost, yet another clearly high-level requirement. A snapshot of the system showing the structure is shown in Figure 2. Here, one can see how test cases linked to the validation requirements clearly state how a given target should shown to be validated. In the example, we state that to have a satisfactory safety factor in the cylinder head means that it has to be above the limit in five individual points. These points are parameterized, and in turn automatically updated by the latest simulation results, hence providing an always up-to-date validation status. This is an example of a data centered way of working.

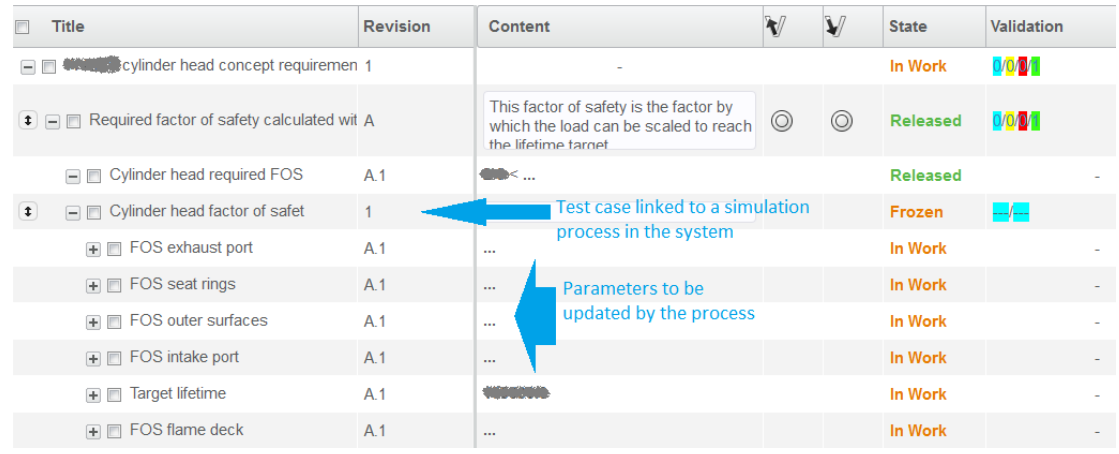

Figure 2. Validation requirements linked to simulations in the Digital Design Platform system

The second cornerstone of our approach is the easy access to simulation data not only for the analyst but for the main consumers of the data, let it be engine experts or designers. The target is to completely get rid of static reports. This is mainly motivated by the study made during the acquisition of the SPDM platform which showed reporting to be one of the major time consumers in the simulation process. Also static reports hardly answer to the digitalization requirements omnipresent in today's industry where validation results play a crucial role for example in condition-based maintenance concepts.

The third key ingredient is simulation democratization, meaning providing pre-configured simulation tools to non-expert users, which is a key selling point for many of the SPDM solutions nowadays and can be implemented in most of the solutions rather readily. However, the problem in successful adoption of democratization depends more on the people involved: on one hand hard work on the simulation side to guarantee robustness and functionality and, on the user side, understanding the limitations of the pre-configured 
workflows. To this end, we propose an organic workflow in which the analyst kicks off the activity and then, for example, if there is a parametric model involved in the development cycle, the designer or engine expert can take over the work in running the parameter configurations based on his expertise instead of leaving the end user with a black box tool.

\section{Conclusions}

In conclusion, the greatest gain from an SPDM solution, based on our current experience, can be gained by taking the system a bit further by connecting it closely to the requirements and the design workflow. This is also the foundation for a digitally enabled product since, without digital design data, it is hard to build digital services around any product. As an example, we see lifetime estimation not only as a validation step, but something we can offer as a tool to the customer creating added value. We have also found out that this kind of a system requires great changes in the thinking for those involved in the product development process and also a bit of courage to let go of the well-established documentbased way of working. One aspect is moving from a file-based approach to a database system, based on our experience it takes some time for the users to get accustomed with trusting the database solution with their data. On the other hand, digitizing processes and checklist for component assurance is sometimes met with resistance, partly due to the openness and transparency, partly due to the extra effort needed for the transition. The most important lesson in the long proof of concept and deployment process has been that you should never consider implementing an SPDM tool as merely a software project, less about the software and more about embracing new ways of working.

\section{References}

[1] Jukka Aho and Tero Frondelius. Analyzing 3 TB field measurement data set. $R a$ kenteiden Mekaniikka, 50(3):224-228, 2017. URL https://doi.org/10.23998/rm. 64942.

[2] Carsten Eller and Joachim Hildebrand. Introduction of SDM at Eberspächer exhaust technology. In NAFEMS World Congress 2017. Nafems.

[3] Tero Frondelius, Pasi Halla-aho, and Antti Mäntylä. Crankshaft development with virtual engine modelling. In CIMAC Congress Helsinki, 2016.

[4] Michael Grieves. A380 snafu, 2006. URL http://innovate.fit.edu/plm/ documents/doc_mgr/912/A380\%20Snafu\%202006.pdf.

[5] Johannes Heilala, Teemu Kuivaniemi, Juho Könnö, and Tero Frondelius. Concept calculation tool for dynamics of generator set common baseframe. Rakenteiden Mekaniikka, 50(3):353-356, 2017. URL https://doi.org/10.23998/rm.64925.

[6] Juho Könnö, Tero Frondelius, Thomas Resch, and Maria Jose Santos-Descalzo. Simulation based grid compliance. In CIMAC Congress Helsinki, 2016.

[7] Asko Kumpula, Joona Vaara, Anton Leppänen, and Tero Frondelius. Nodular cast iron ONERA fatigue model fitting. Rakenteiden Mekaniikka, 50(3):179-181, 2017. URL https://doi.org/10.23998/rm.64740. 
[8] Anton Leppänen, Asko Kumpula, Joona Vaara, Massimo Cattarinussi, Juho Könnö, and Tero Frondelius. Thermomechanical fatigue analysis of cylinder head. Rakenteiden Mekaniikka, 50(3):182-185, 2017. URL https://doi.org/10.23998/rm.64743.

[9] Bob Tickel. The future of modelling and simulation at Cummins. In NAFEMS World Congress 201\%. Nafems.

[10] Miikka Väntänen, Joona Vaara, Jukka Aho, Jukka Kemppainen, and Tero Frondelius. Bayesian sequential experimental design for fatigue tests. Rakenteiden Mekaniikka, 50(3):201-205, 2017. URL https://doi .org/10.23998/rm.64924.

Juho Könnö, Hannu Tienhaara and Tero Frondelius

Wärtsilä

Järvikatu 2-4

65100 Vaasa

juho.konno@wartsila.com, hannu.tienhaara@wartsila.com,

tero.frondelius@wartsila.com 